\title{
Endometriosis in Adolescence: Challenges and Opportunities for Managing Future Infertility
}

Efthimios Deligeoroglou $^{{ }^{\star}}$, Vasileios Karountzos ${ }^{1}$, Pandelis Tsimaris $^{1}$ and Evangelia Deligeoroglou ${ }^{1}$

${ }^{1}$ Division of Pediatric-Adolescent Gynecology \& Reconstructive Surgery, Athens, Greece

\section{Abstract}

Endometriosis is defined as the presence of endometrial stroma and glands outside the normal uterus. Received: November 06, 2018 The prevalence of endometriosis in adolescents undergoing laparoscopy for chronic pelvic pain is reported Accepted: December 17, 2018

to be between $19 \%$ and $73 \%$. Interestingly, endometriosis has also been identified in premenarcheal girls Published: December 19, 2018 with some breast development. Several factors have been incriminated for endometriosis, while no single theory can explain the variety of symptoms. Genetic factors seem to play a role, while lifestyle characteristics and environmental factors are likely related to the development of the disease. The main symptoms during diagnosis of endometriosis in adolescence, is chronic pelvic pain (27\%-96\%) and dysmenorrhea (18\%-100\%). Medical history and clinical examination are of great importance, while imaging exams are very helpful during evaluation of these girls, while endometriosis can only be diagnosed by visual inspection during laparoscopy, ideally confirmed by histology. Treatment options include not only medical regimens, with Non-Steroidal-Anti-Inflammatory Drugs and Combined Oral Contraceptives been the most common used, and other medications such as Danazol, Progestins, GnRH agonists with Add-Back therapy and cyproterone acetate, but also surgical treatment. Surgical management alone or in combination with postoperative hormonal suppression seems to improve future fertility options of adolescents with endometriosis.

\section{Publication History:}

\section{Keywords:}

Adolescence, Endometriosis, Treatment, Fertility

\section{Introduction}

Endometriosis is defined as the presence of endometrial stroma and glands outside the normal uterus. As reported in the past by the Endometriosis Association Registry a total of $38 \%$ of women diagnosed with endometriosis may have symptoms before the age of 15 , while a mean number of 4.2 physicians have examined the adolescent before final diagnosis is set [1]. On the other hand, a range between $19 \%$ and $73 \%$ of adolescents undergoing laparoscopy for chronic pelvic pain are diagnosed with endometriosis. The same was found by a study of Goldstein et al. [2] who reported that the prevalence of endometriosis found at laparoscopy in a prospective study of adolescent females with pelvic pain is $47 \%$, while other studies have shown a prevalence of 25 $38 \%$ for these adolescents. [3,4]. A $66 \%$ of adult women have reported the onset of pelvic symptoms before the age of 20 according to the Endometriosis Association.

It is of great importance that $50-70 \%$ of adolescents with pelvic pain, who have received Combined Oral Contraceptives (COCs) and/or Nonsteroidal Anti-Inflammatory Drugs (NSAIDs), but no responding to them, have signs of endometriosis during laparoscopy. Interestingly, endometriosis has also been identified in premenarcheal girls with some breast development $[5,6]$. This can be explained by the theory of embryonic müllerian rests or coelomic metaplasia as opposed to retrograde menses.

\section{Pathophysiology}

Several factors have been incriminated for endometriosis, while no single theory can explain the variety of symptoms. Sampson [7] was the first who reported that during menstruation endometrial cells regurgitate through the fallopian tubes and implant in the pelvis. Another theory has proposed that metaplastic cells transform into endometrial cells, [8] and these metastasize through lymphatic and vascular channels, resulting in endometriosis [9]. This theory can explain the findings of endometriosis in other tissues such as the lung, brain, and skin. Other multi-factorial hypotheses with immunological, anatomical and genetic mechanisms, leading to dysfunction in the ectopic endometrium can explain several other endometriosis cases. Theoretically, all women should have been diagnosed with endometriosis, due to normal retrograde menstruation at the pelvis in every cycle [10]. The above theories, explain why some women diagnosed with endometriosis and others not, paying attention in individual features, such as family history of endometriosis, early menarche and exposure to circulating steroid hormones, body mass index during late childhood and early adolescence. Moreover, lifestyle characteristics and environmental factors are likely related to the development of the disease playing an epigenetic role. Positive family history has been reported by many studies [11], even though this association cannot only be explained by genetic mechanisms. It is important that the disease among first-degree relatives is six to nine times higher than in the population $[12,13]$.

An early menarche is also positively associated with endometriosis [14], due to the fact that these girls are more likely overweight, with higher levels of adipose fat tissue and circulating steroid hormones $[15,16]$. Another factor that seems to play a role in the inverse relation between childhood and early adolescence body size and the incidence of laparoscopically confirmed endometriosis is anovulation due to insulin resistance and hyperinsulinemia in obese pre-adolescent girls [17].

Finally, endometriosis can only be diagnosed by visual inspection during laparoscopy, ideally confirmed by histology and can present

"Corresponding Author: Prof. Efthimios Deligeoroglou, Department of Obstetrics \& Gynecolog National and Kapodistrian University of Athens, Medical School, 145 Michalakopoulou Str., 11527 Athens, Greece, Fax: +302107798111, +302107233330; E-mail: deligeoroglou@yahoo.gr

Citation: Deligeoroglou E, Karountzos V, Tsimaris P, Deligeoroglou E (2018) Endometriosis in Adolescence: Challenges and Opportunities for Managing Future Infertility. Int J Gynecol Clin Pract 5: 145. https://doi.org/10.15344/23944986/2018/145

Copyright: (c) 2018 Deligeoroglou et al. This is an open-access article distributed under the terms of the Creative Commons Attribution License, which permits unrestricted use, distribution, and reproduction in any medium, provided the original author and source are credited. 
as peritoneal disease with typical or subtle lesions, ovarian endometriotic cysts or deeply infiltrative disease or as a combination of these features. Different Classification systems have been used at the past in order to set different stages of the disease. The degree of endometriosis can be staged by laparoscopy as minimal, mild, moderate or severe according to the classification of the American Society of Reproductive Medicine [ASRM-former American Fertility Society (AFS)] [18]. Studies regarding the ASRM classification system have shown that adolescents with endometriosis, hadeither minimal $(50 \%)$, mild (27\%), moderate $(18 \%)$ or severe $(14 \%)$ disease. Other classification systems include the Endoscopic Endometriosis Classification I-IV by Semm (EEC I-IV) [19], the Acosta classification [20] or the staging system proposed by Kistner et al. [21] with a scale of I-IV. The variety of studies and classification systems agree that the prevalence and severity of the endometriosis is believed to significantly increase with age therefore is considered as a progressive disease [22]

\section{Diagnosis}

The main symptoms during diagnosis of endometriosis in adolescence, is chronic pelvic pain (27\%-96\%) and dysmenorrhea $(18 \%-100 \%)[23,24]$. Acyclic pain seems to be more common in adolescents than in adults. Other symptoms that can support diagnosis are gastrointestinal symptoms, urinary symptoms, irregular menses, dyspareunia, pelvic mass, subfertility, constitutional symptoms and depression/anxiety [23]. In all adolescents is offered apain diary, in order to document frequency and all characters of pain. Smorgick et al. have reported that the prevalence of comorbid chronic pain syndromes (56\%) and mood disorders (48\%) in adolescents suffering from endometriosis is not uncommon, while irritable bowel syndrome, interstitial cystitis/painful bladder syndrome and chronic headaches can be found in up to $25 \%, 16 \%$ and $19 \%$ respectively in these adolescents [24].

In a study by Laufer et al. [25], 90.6\% of adolescents with endometriosis had acyclic pain versus $69 \%$ in the adult population as reported above [26]. Müllerian anomalies, especially those with outflow tract obstructions, are statistically significantly positively correlated with endometriosis, being an independent risk factor. This was shown by a study be Yang et al [27] who reported that genital tract malformations can present in up to $24 \%$ of patients with endometriosis. The majority of adolescents have early stage disease, but up to $33 \%$ of them have advanced disease. Fedele et al. [28] found no correlation between severity of pain symptoms and stage of the disease or site of the endometriotic lesions, while an ovarian endometrioma is the most common presentation of advanced endometriosis in adolescents. Recent studies have report a large number of cases of adolescents with Stage III and IV endometriosis. The adult literature reports Stage I disease in $30 \%-39 \%$, Stage II in 12\%-13\%, Stage III in $27 \%-35 \%$ and Stage IV in $13 \%-28 \%$ [29,30]. Even though adolescents may present with advanced stages of endometriosis, these number are fewer comparing with adults.

Red lesions are the most common lesions seen in adolescents, with atypical lesions being common as well. Two studies, one by Davis et al [31] and another by Reese et al [32] showed that the vast majority of lesions in adolescent populations with endometriosis are red lesions, while a large number of these lesions were correlated with severe dysmenorrhea, with complaints of abdominal pain, nausea, constipation and diarrhea. Another study reported atypical red vascular lesions in $60 \%$ of adolescents compared to only $20 \%$ of nonadolescents [30]. Clear lesions are common in adolescent endometriosis but often difficult to visualize and evaluate. Peritoneal defects, or windows, which are possible manifestations of endometriosis, are very common in adolescents. The reported incidence in adolescents is around $10 \%-18.4 \%$ as quoted in several studies [33].
Past medical history, family history and physical examination are mandatory during evaluation and management of adolescents with a possible endometriosis. Several other pathologies, such as appendicitis, pelvic inflammatory disease, müllerian anomalies or outflow obstruction, bowel disease, hernias, musculoskeletal disorders, and psychosocial complaints should be excluded in order to set the diagnosis. Inspection of the girl for a possible estrogendominant body configuration with peripheral fat distribution and for breast and pubic hair development according to the Tanner classification system is of great importance [23].

A patent outflow should be performed in all adolescent by placing a Q-tip into the vaginal canal. This is very helpful, in order to exclude a possible transverse vaginal septum, vaginal agenesis, or agenesis of the lower vagina. For virgo adolescents pelvic examination cannot be performed, therefore, a rectal-abdominal examination, even discomfort for adolescents, in the dorsal lithotomy position, may be helpful to determine if a pelvic mass is present. Attention should be given in the existence of both diffuse and focal pelvic tenderness [23].

Imaging exams are very helpful during evaluation of these girls. Ultrasonography and magnetic resonance evaluate anatomical structures, but are not specific for diagnosing of endometriosis. According to some studies, MRI can detect endometrial implants with a sensitivity as high as $60 \%$, while this method can be used in order to follow up adolescents' response to treatment, even though its cost is high [34]. Blood tests, such as CA 125, are very sensitive, but it is not specific and, thus, is not helpful in the diagnosis of adolescent endometriosis. No data exist regarding the use of CA 125 to monitor the clinical progression or regression of disease in adolescents with endometriosis [35].

Symptomatic adolescents should be evaluated laparoscopically when standard treatment of pelvic pain or dysmenorrhea is not effective. Endometriosis should be staged using the revised criteria of the American Society of Reproductive Medicine point-based classification system as mentioned above [18]. Biopsying during laparoscopy sites of apparent endometriosis, especially atypical lesions, in order to confirm the diagnosis and avoid mislabeling a patient is of great importance, while biopsying normal appearing peritoneum should be left at the surgeon's discretion because it is somewhat controversial [36].

Progression of the disease in adolescents has been a topic of argument among researchers. In 2010, Unger and Laufer [37] published the case reports of three adolescents, aged between 13 and 16 years, suffering from severe pelvic pain and diagnosed with Stage I endometriosis at the time of laparoscopy. Reese et al. [32] presented 39 adolescents, with 4 patients (18\%), in the two older age groups (1617 and 18-20 years), suffering from Stage III or IV. Tandoi et al. [38] studied 57 women aged 21 years or younger over a 5 -year period and in 32 (56\%) observed a recurrence of the disease after surgery. Its rate increased with time from surgery, with no apparent association with site or stage of the disease, type of surgery, and post-surgical medical treatment. Yang et al. [27] reported that $45.7 \%$ of 35 adolescents included in the study, suffered from disease recurrence with an average time of recurrence of 33.4 months.

\section{Treatment}

Treatment algorithm for adolescents presenting with dysmenorrhea according to the American College of Obstetricians and Gynecologists is summarized in Figure 1 [39].

Recommendations include initiation of treatment with NSAIDs and COCs. In case of symptoms persistence, after 3 months, a 
diagnostic laparoscopy should be offered for these girls [39]. As reported above, lesions seen in adolescents' pelvis, during laparoscopy are different from the typical powder burn lesions seen in adults [40]. Endometriosis symptoms control, prevention of disease progression and preservation of fertility are primary goals of treatment. Medical and surgical options are available for the management of endometriosis.

\section{Medical management}

\section{NSAIDs}

NSAIDs can be used as empiric treatment during management of dysmenorrhea in adolescents, even though the diagnosis of endometriosis has not been set yet.

\section{Combined oral contraceptives (COCs)}

COCs are typically the first line treatment and can be used as well as empiric treatment. Acting by ovulation inhibition, they decrease gonadotropin levels and therefore reduce menstrual flow and cause decidualization of endometriotic implants. Another role of COCs is the decrease of cell proliferation, as well as the reduction of eutopic endometrium. COCs can be used as continuous treatment in order to induce amenorrhea, with therapy being suppressive and not curative, while stopping treatment for more than 6 months, can lead to symptoms recurrence. Finally, according to Cochrane Database of 2007 there are no sufficient data regarding long-term benefits of COC in the treatment of endometriosis [41].

\section{Progestins}

Progesterone agents include medroxyprogesterone acetate (MPA) and 19 nortestosterone derivatives, such as norethindrone and norgestrel. These agents lead to decidualization and atrophy not only in ectopic, but as well in eutopic endometrial tissue. 20 to $30 \mathrm{mg}$ daily or the depot form of $150 \mathrm{mg}$ every 3 months of medroxyprogesterone acetate can be used in order to treat symptoms of dysmenorrhea or adolescents' endometriosis. It is important that up to $70 \%$ to $80 \%$ of girls suffering from endometriosis show symptoms improvement. On the other hand the benefits of long-term use of progestin therapy needs to be weighed against impaired bone mineralization secondary to the hypoestrogenic environment induced by progestins, with the risk for osteoporotic fractures been yet unknown, as reported also by the U.S. Food and Drug Administration [42,43]. Other side effects include weight gain, bloating, mood lability and irregular bleeding.

\section{Danazol}

Danazol is a 17-ethinyl testosterone derivative with an efficacy being equivalent to a variety of $\mathrm{GnRH}$ agonists in treating endometriosis. Its androgenic effects, affecting sex-hormone-binding globulin levels, resulting in an increase of free testosterone. Buttram [44] had studied 220 patients, complaining about weight gain, depression, muscle cramps, decreased breast size, flushing, oily skin and hair, acne, hirsutism, irreversible deepening of the voice, and skin rash. Among them $7 \%$ discontinued the drug secondary to intolerable side effects and this is enhanced by the fact that patients using GnRH agonists reported a better quality of life compared to them using danazol. Finally, due to the fact that this agent is poorly tolerated by adolescents is not widely utilized in endometriosis management [45].

\section{Cyproterone acetate}

Cyproterone acetate (CPA) is a 17-hydroxyprogesterone derivative with antiandrogenic and antigonadotropic properties. As reported in a study by Fedele et al. [46] $27 \mathrm{mg} /$ day oral CPA with $0.035 \mathrm{mg}$ ethinyl estradiol could be used to treat women with endometriosis successfully, while another study by Vercellini et al. [47] including 90 women, who received either $12.5 \mathrm{mg} /$ day CPA or a daily COC $(0.02 \mathrm{mg}$

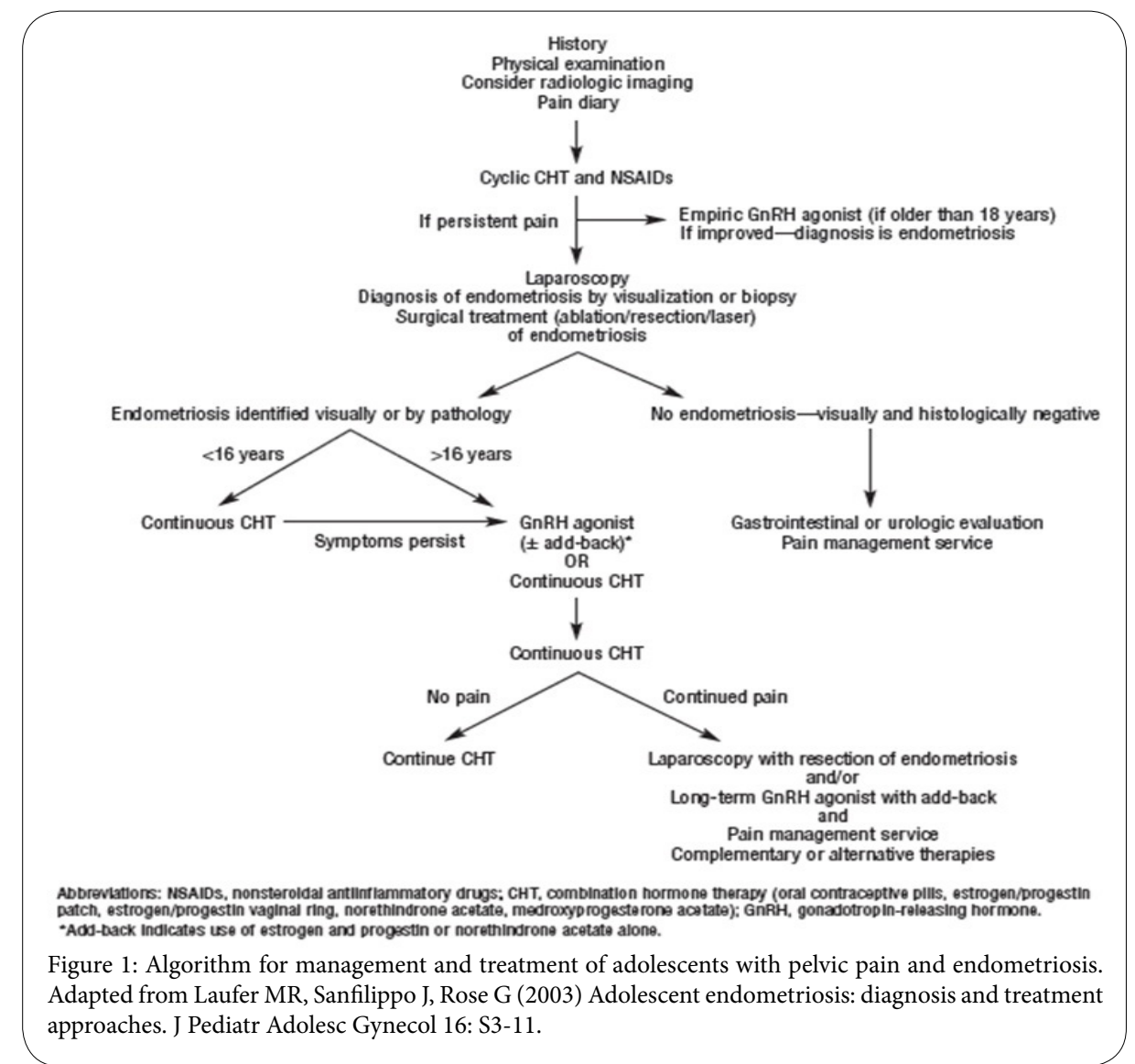


ethinyl estradiol $+0.15 \mathrm{mg}$ desogestrel) for 6 months, showed that after 6 months pain scores were reduced in both groups. This supports the idea that girls in whom estrogens are contraindicated, CPA may be an alternative sufficient treatment.

\section{GnRH agonists}

GnRH agonists are very effecting in treating adolescent endometriosis and alleviate symptoms associated with endometriosis. Acting by inducing menopause with binding to the GnRH receptors in the pituitary, they result to cessation of pituitary gonadotropin release and subsequently to amenorrhea. According to the Cochrane Group reviewed the efficacy of GnRH agonists versus COCs in the treatment of endometriosis, GnRH agonists are more effective than COCs. GnRH agonists include leuprolide acetate, nafarelin, buserelin, and goserelin. Leuprolide can be given as a 3.75-mg injection every 4 weeks or $11.25-\mathrm{mg}$ injection every 12 weeks. It is of great importance to remember that the use of $\mathrm{GnRH}$ agonists alone is generally limited to patients more than 16 years of age and for a period no more than 6 months [48].

\section{Add back therapy}

In order to prevent side effects of pseudomenopause associated with GnRH agonist like vasomotor symptoms, vaginal dryness, and mood swings, hormonal "add-back" options are recommended. These include norethindrone acetate (5-mg daily) and combined conjugated estrogens/medroxyprogesterone acetate (0.625/2.5$\mathrm{mg}$ daily). Adolescents accruing bone mass up to the age of 20 years, therefore initiation of GnRH agonists in this age should always begin in combination with add-back therapy, while BMD monitoring should be offered every 2 years. Calcium and Vitamin D supplementation should be given in all these girls in order to avoid bone demineralization [49].

\section{Surgical treatment}

Surgical options in adolescent endometriosis include laparoscopy rather than laparotomy. The role is both diagnostic and therapeutic and usually a specialized physician in laparoscopy and adolescent endometriosis is preferred to perform the procedure. Surgery should be timed in the follicular phase of menstrual cycle, in order to avoid future possibility of recurrences and adhesions. First port should be intraumbilical and the lateral ports should be placed close to the pubic bone for cosmetic superiority. The goal of surgical treatment is to remove visible areas of endometriosis and restore normal anatomy by lysis ofadhesions. The procedure seems to improving endometriotic symptoms in $38 \%$ to $100 \%$ of adolescents [50]. Laser vaporization, unipolar or bipolar coagulation, and endocoagulation are the methods used, with no one technique has been shown to be superior to any other.

Surgical treatment seems to improve pain in adolescents with endometriosis. This was summarized in a meta-analysis by Janssen et al. [51], in which girls were treated either with ablation or excision of endometriosis and pain improvement was shown. Furthermore, Yang et al. [27] concluded that there was a decrease in chronic pelvic pain (by $23.5 \%$ ) and dyspareunia (by $11.8 \%$ ) after complete excision of endometriotic lesions, while in a study be Dun et al. [23], 64\% reported resolved pain and $16 \%$ reported improvement of pain at 1 year after the laparoscopic excision and ablation of lesions.

Surgical treatment can also improve fertility options in adolescence. In a retrospective case series to assess the long-term fertility outcomes in young women after laparoscopic surgery (excision and ablation) for endometriosis, a long-term pregnancy rate of $71.4 \%$ of which $>80 \%$ were achieved without assisted reproductive technology (ART) was shown, with most of the patients who conceived had Stage I/II disease [52].

Surgery is also very helpful in reducing disease progression and/ or recurrence. In some studies is reported that complete laparoscopic excision by experts can significantly reduce the recurrence rates of endometriosis in adolescents, while Yang et al. [27] found zero rate of recurrence (diagnosed visually or histologically) after complete laparoscopic excision of the disease in teenagers at a repeat laparoscopy for pain. Even though the frequency of adolescents undergoing laparoscopy for persistent recurrent pain is $47.1 \%$ the rate of endometriosis found at surgery was zero [53].

On the other hand, postoperative hormonal suppression should be offered to adolescents in order to treat symptoms and to prevent progression and/or recurrence of the disease, while the role of postoperative medical therapy in conjunction with surgery in improving future fertility of adolescents with endometriosis has not been evaluated. Moreover, the conjunction of surgery with postoperative medical therapy does not seem to slow disease progression and/or recurrence. The recurrence rate of endometriosis in young women appears to be higher than in older women. In a retrospective cohort study of 57 women, aged $\leq 21$ years, who were treated initially by excisional surgery, was shown that the rate of recurrence of symptoms during a follow up-period of 5 years was $56 \%$. The study also showed that the postoperative medical therapy did not influence the recurrence rates [38].

As reported above, a variety of medical therapies have been used in treating endometriosis during adolescence. Even though further studies needed, in order to conclude which medical therapy is superior to another, GnRH agonists seem to be more effective compared with COCs and progestins to prevent disease recurrence. Combination norethindrone acetate plus conjugated equine estrogens as add-back therapy, appears to be more effective for increasing total bone mineral content, bone mineral density and lean mass than norethindrone acetate monotherapy [54,55]. Levonorgestrel intrauterine system (LNG-IUS) is accepted for use in the adolescent population for contraception and menorrhagia, but there are not enough data regarding its effectiveness in the treatment of adolescent endometriosis.

\section{Endometrial cysts}

There are very few data about endometriosis and endometriomas in adolescents and young women. A study reviewing 15 years of ovarian masses in infants, children and adolescents reported no endometriomas [56]. Ovarian endometriomas are usually correlated with more advance stage of the disease.

As it is easily understood, these girls are present with more frequent pain. A retrospective study of 63 adolescents with endometrioma found bilateral disease in $22.22 \%$, while endometrioma in the right ovary seems to be more frequent than a left endometrioma (65\% vs. $57 \%)$. In these cases the preferable surgery is a combined technique of cystectomy and cauterization of the capsule [57]. Interestingly, in a review by Gordts et al. [58] was found that early ablative surgery can contribute to a lower morbidity, relief of symptoms, and a better quality of life, while in another recent published study have reported recurrence rates of endometrioma per patient at 24, 36, 60 and 96 months after laparoscopic cyst enucleation for ovarian endometrioma being $6.4 \%, 10 \%, 19.9 \%$ and $30.9 \%$, respectively. All these adolescents had stage III or IV of the disease. 
Citation: Deligeoroglou E, Karountzos V, Tsimaris P, Deligeoroglou E (2018) Endometriosis in Adolescence: Challenges and Opportunities for Managing Future Infertility. Int J Gynecol Clin Pract 5: 145. https://doi.org/10.15344/2394-4986/2018/145

\section{Future Trends}

Selective estrogen receptor modulators (SERMS) and selective progesterone receptor modulators (SPRMs) are the new treatment options for adolescent endometriosis. However, we have not yet human studies for both drug groups. Both are acting by suppressing estrogen dependent endometrial growth without the adverse systemic effects of hypoestrogenism, like vasomotor symptoms and loss of BMD. Another treatment options, is the use of aromatase inhibitors. This is a key enzyme in estrogen biosynthesis, appears to be over-expressed in sites of endometriosis. This drug acting by reducing ovarian and local production of estrogens, therefore can be used in treatment of adolescent endometriosis. Finally, autoimmune modulators may be an effective method of disease treatment, with anti-tumor necrosis factor therapies have been already successfully used to reduce endometriotic growth in animal models, being a promising future treatment method $[59,60]$.

\section{Follow-up}

A careful follow-up of adolescents with endometriosis is mandatory, due to the fact that it can be a life-long disease. Patient should be examined every 3 to 6 months. During this time, a pain calendar should be used in order to monitor the pain, while concerns regarding future fertility and quality of life should be addressed. Unless contraindicated, most patients should be put on COCs after surgery. If the patient does not respond to surgery or has recurrence of symptoms, other treatment modalities should be considered. A multidisciplinary approach is usually needed, including a gastroenterologist, psychologist and urologist.

\section{Issues for Future Consideration}

Future studies should be focused on the role of early diagnosis of endometriosis and treatment in progression and advancement of the disease. Question remaining regarding, how the adolescent daughter of a woman, who had no pelvic pain, but stage IV endometriosis and infertility should be treated. Is it important for that girl to be evaluated and treated, even though she has no pelvic pain, in order to exclude the possibility of endometriosis.

\section{Conclusions}

Adolescent endometriosis is not uncommon being a progressive disease. Pain is the main symptom, especially dysmenorrhea and chronic pelvic pain. NSAIDs and COCs can be used as first line medical treatment during management of adolescent endometriosis, but in case of symptoms persistence, the girl should undergo a laparoscopy, with the likelihood of endometriosis during laparoscopy being up to $50 \%$. The appearance of lesions found at laparoscopy in adolescents may differ from that in adults, while COCs, DMPA, GnRH agonists and surgical ablation tend to be the practical treatment modalities in this age group. Primary goals are alleviation of pain symptoms, avoidance of disease recurrence and assurance of future fertility preservation. A multidisciplinary approach to pelvic pain with the assistance of pain treatment services is usually recommended, while future work for adolescents should focus on developing safe, minimally invasive, treatment techniques.

\section{Competing Interests}

The author declare no competing interests.

\section{Reference}

1. Ballweg ML (2003) Big picture of endometriosis helps provide guidance on approach to teens: comparative historical data show endo starting younger, is more severe. J Pediatr Adolesc Gynecol 16: 21-26.

2. Goldstein DP, De Cholnoky C, Emans SJ (1980) Adolescent endometriosis. J Adolesc Health Care 1: 37-41.

3. Vercellini P, Fedele L, Arcaini L, Bianchi S, Rognoni MT, et al. (1989) Laparoscopy in the diagnosis of chronic pelvic pain in adolescent women. J Reprod Med 34: 827-830.

4. Kontoravdis A, Hassan E, Hassiakos D, Botsis D, Kontoravdis N, et al. (1999) Laparoscopic evaluation and management of chronic pelvic pain during adolescence. Clin Exp Obstet Gynecol 26: 76-77.

5. Batt RE, Mitwally MF (2003) Endometriosis from thelarche tomidteens: pathogenesis and prognosis, prevention and pedagogy. J Pediatr Adolesc Gynecol 16: 337-347.

6. Marsh EE, Laufer MR (2005) Endometriosis in premenarcheal girls without an associated obstructive anomaly. Fertil Steril 83: 758-760.

7. Sampson JA (1927) Peritoneal endometriosis due to the menstrual dissemination of endometrial tissue into the peritoneal cavity. Am J Obstet Gynecol 14: 422-469.

8. Meyer R (1909) Uber entzundlichen eterope epithel wucherung enim weiblichen Genetalgebiet und ubereinebis in die Wurzeldes Mesocolon ausgedehnte benigne Wucherung des Darmepithel. Virch Arch Pathol Anat 195: 487 .

9. Halban J (1924) Hysteroadenos ismetastica. Wien Klin Wochenschr 37:1205.

10. Fraser IS (2008) Recognising, understanding and managing endometriosis. J Hum Reprod Sci 1: 56-64.

11. Shah DK, Missmer SA (2011) Scientific investigation of endometriosis among adolescent. J Pediatr Adolesc Gynecol 24: S18-S19.

12. Arvanitis DA, Goumenou AG, Matalliotakis IM, Koumantakis EE, Spandidos DA (2001) Low-penetrance genes are associated with increased susceptibility to endometriosis. Fertil Steril 76: 1202

13. McDonough PG (2002) Genome movement and pediatric adolescent gynecology: genomic techniques. J Pediatr Adolesc Gynecol 15:123.

14. Treloar SA, Bell TA, Nagle CM, Purdie DM, Green AC (2010) Early menstrual characteristics associated with subsequent diagnosis of endometriosis. Am Job stetGynecol 202: 534-536.

15. Kaplowitz PB, Slora EJ, Wasserman RC, Pedlow SE, Herman-Giddens ME (2001) Earlier onset of puberty in girls: relation to increased body mass index and race. Pediatrics 108: 347-353.

16. Nagle CM, Bell TA, Purdie DM, Treloar SA, Olsen CM, et al. (2009) Relative weight at ages 10 and 16 years and risk of endometriois: acase-controle analysis. Hum Reprod 24: 1501-1506.

17. Vitonis AF, Baer HJ, Hankinson SE, Laufer MR, Missmer SA, et al. (2010) A prospective study of body size during childhood and early adulthood and the incidence of endometriosis. Hum Reprod 25: 1325-1334.

18. Revised American Society for Reproductive Medicine Classification of Endometriosis: 1996 (1997) Fertil Steril 67: 817-821.

19. Semm K (1984) Operationslehre für endoskopische Abdominalchirurgie, Stuttgart, New York: Schattauer Verlag.

20. Acosta AA, Buttram VC Jr, Besch PK, Malinak LR, Franklin RR, et al. (1973) A proposed classification of pelvic endometriosis. Obstet Gynecol 42: 19-25.

21. Kistner RW, Siegler AM, Behrman SJ (1977) Suggested classification for endometriosis: relationship to infertility. Fertil Steril 28: 1008-1010.

22. Brosens IA (1997) Endometriosis - a disease because it is characterized by bleeding. Am J Obstet Gynecol 176: 263-267.

23. Dun EC, Kho KA, Morozov VV, Kearney S, Zurawin JL, et al. (2015) Endometriosis in adolescents. JSLS 19: 1-8.

24. Smorgick N, Marsh CA, As-Sanie S, Smith YR, Quint EH, et al. (2013) Prevalenceof pain syndromes, mood conditions, and asthma inadolescents and young women with endometriosis. J Pediatr Adolesc Gynecol 26: 171175.

25. Laufer MR, Goitein L, Bush M, Cramer DW, Emans SJ, et al. (1997) Prevalence of endometriosis in adolescent girls with chronic pelvicpain not responding to conventional therapy. J Pediatr Adolesc Gynecol 10: 199-202.

26. Falcone T, Lebovic DI (2011) Clinical management of endometriosis. Obstet Gynecol 118: 691-705. 
Citation: Deligeoroglou E, Karountzos V, Tsimaris P, Deligeoroglou E (2018) Endometriosis in Adolescence: Challenges and Opportunities for Managing Future Infertility. Int J Gynecol Clin Pract 5: 145. https://doi.org/10.15344/2394-4986/2018/145

27. Yang Y Wang Y, Yang J, Wang S, Lang J, et al. (2012) Adolescent endometriosisin China: a retrospective analysis of 63 cases. J Pediatr Adolesc Gynecol 25: 295-299.

28. Fedele L, Parazzini F, Bianchi S, Arcaini L, Candiani GB (1990) Stage and localization of pelvic endometriosis and pain. Fertil Steril V 53: 155-158.

29. Roman JD (2010) Adolescent endometriosis in the Waikato region of New Zealanda comparative cohort study with a mean follow up time of 2.6 years. Aust N Z J Obstet Gynaecol 50: 179-183.

30. Vicino M, Parazzini F, Cipriani S, Frontino G (2010) Endometriosis inyoung women: the experience of GISE. J Pediatr Adolesc Gynecol 23: 223-225.

31. Davis GD, Thillet E, Lindemann J (1993) Clinical characteristics of adolescent endometriosis. J Adolesc Health 14: 362-368.

32. Reese KA, Reddy S, Rock JA (1996) Endometriosis in an adolescent population: the Emory experience. J Pediatr Adolesc Gynecol 9: 125-128.

33. Kalu E, McAuley W, Richardson R (2008) Teenagers, adolescents, endometriosis and recurrence: a retrospective analysis of recurrence following primary operative laparoscopy. Gynecol Surg 5: 209-212.

34. Umaria N, Olliff JF (2001) Imaging features of pelvic endometriosis. $\mathrm{Br}$ Radiol 74: 556-562.

35. Cheng YM, Wang ST, Chou CY (2002) Serum CA-125 in preoperative patients at high risk for endometriosis. Obstet Gynecol 99: 375-380.

36. Walter AJ, Hentz JG, Magtibay PM, Cornella JL, Magrina JF (2001) Endometriosis: correlation between histologic and visual findings at laparoscopy. Am J Obstet Gynecol 184: 1407-1413.

37. Unger CA, Laufer MR (2011) Progression of endometriosis in non-medically managed adolescents: a case series. J Pediatr Adolesc Gynecol 24: 21-23.

38. Tandoi I, Somigliana E, Riparini J, Ronzoni S, Vigano P, et al. (2011) High rate of endometriosis recurrence in young women. J Pediatr Adolesc Gyneco 24: 376-379.

39. Laufer MR, Sanfilippo J, Rose G (2003) Adolescent endometriosis: diagnosis and treatment approaches. J Pediatr Adolesc Gynecol 16: 3-11.

40. Laufer MR (1997) Identification of clear vesicular lesions of atypical endometriosis: a new technique. Fertil Steril 68: 739-740.

41. Davis L, Kennedy SS, Moore J (2007) Modern combined oral contraceptives for pain associated with endometriosis. Cochrane Database Syst Rev 3: CD001019.

42. Vercellini P, De Giorgi O, Oldani S, Cortesi I, Panazza S, et al. (1996) Depot medroxyprogesterone acetate versus an oral contraceptive combined with very-low-dose danazol for long-term treatment of pelvic pain associated with endometriosis. Am J Obstet Gynecol 175: 396-401.

43. Bahamondes L, Perrotti M, Castro S, Faúndes D, Petta C, et al. (1999) Forearm bone density in users of depoprovera as a contraceptive method. Fertil Steril 71: 849-852.

44. Buttram VC, Reiter RC, Ward S (1985) Treatment of endometriosis with danazol: report of a 6-year prospective study. Fertil Steril 43: 353.

45. Selak V, Farquhar C, Prentice A, Singla A (2002) Danazol for pelvic pain associated with endometriosis. In: The Cochrane Library. Oxford: Update Software Ltd.

46. Fedele L, Arkainin L, Bianchi S, Baglioni A, Vercellini $P$, et al. (1989) Comparison of cyproterone acetate anddanazol in the treatment of pelvic pain associated with endometriosis. Obstet Gynecol 73: 100-104.

47. Vercellini P, De Giorgi O, Mosconi P, Stellato G, Vicentini S, et al. (2002) Cyproterone acetate versus acontinuous monophasic oral contraceptive in the treatment of recurrent pelvicpain after conservative surgery for symptomatic endometriosis. Fertil Steril 77: 52-61.

48. Regidor PA, Regidor M, Schmidt M, Ruwe B, Lübben G, et al. (2001) Prospective randomized study comparing the $\mathrm{GnRH}$-agonist leuprorelin acetate and the gestagenlynestrenolin the treatment of severe endometriosis. Gynecol Endocrinol 15: 202-209.

49. Laufer MR (2008) Current approaches to optimizing the treatment of endometriosis in adolescents. Gynecol Obstet Investigation 66: 19-27.

50. Sutton J, Ewen SP, Whitelaw N, Haines P (1994) Prospective, randomized, double blind, controlled trial of laser laparoscopy in the treatment of pelvic pain associated with minimal, mild and moderate endometriosis. Fertil Steri 4: 696-700.

51. Janssen EB, Rijkers ACM, Hoppenbrouwers K, Meuleman C, D'Hooghe TM, et al. (2013) Prevalence of endometriosis diagnosed by laparoscopy in adolescents with dysmenorrhea or chronic pelvic pain: a systematic review. Hum Reprod Update 19: 570-582.

52. Wilson-Harris BM, Nutter B, Falcone T (2014) Long-term fertility after laparoscopy for endometriosis-associated pelvic pain in young adult women. J Minim Invasive Gynecol 21: 1061-1066.
53. Rimbach S, Ulrich U, Schweppe KW (2013) Surgical therapy of endometriosis: challenges and controversies. Geburtshilfe Frauenheilkd 73: 918-923.

54. Sadler Gallagher J, Feldman HA, Stokes NA, Laufer MR, Hornstein MD, et al. (2017) The Effects of Gonadotropin-Releasing Hormone Agonis Combined with Add-Back Therapy on Quality of Life for Adolescents with Endometriosis: A Randomized Controlled Trial. J Pediatr Adolesc Gynecol 30: 215-222.

55. Divasta AD, Laufer MR, Gordon CM (2007) Bone density in adolescents treated with a GnRH agonist and add-back therapy for endometriosis. J Pediatr Adolesc Gynecol 20: 293-297.

56. Cass DL, Hawkins E, Brandt ML, Chintagumpala M, Bloss RS et al. (2001) Surgery for ovarian masses in infants, children, and adolescents: 102 consecutive patients treated in a 15-year period. J Pediatr Surg 36: 693-699.

57. Özyer S, Uzunlar Ö, Özcan N, Yeşilyurt H, Karayalçin R, et al. (2013) Endometriomas in adolescents and young women. J Pediatr Adolesc Gynecol 26: 176-179.

58. Gordts S, Puttemans P, Gordts S, Brosens I (2015) Ovarian endometrioma in the adolescent: a plea for early-stage diagnosis and full surgical treatment. Gynecol Surg 12: 21-30

59. Chwalisz K, Garg R, Brenner RM, Schubert G, Elger W, et al. (2002) Selective progesterone receptor modulators (SPRMs): a novel therapeutic concept in endometriosis. Ann N Y Acad Sci 955: 373-388.

60. Buelke-Sam, Bryant HU, Francis PC (1998) The selective receptor modulator raloxifene: an overview on non-clinical pharmacology and reproductive and developmental testing. Hum Reprod Update 6: 413-418. 